\title{
Why do anti-inflammatory signals of bone marrow-derived stromal cells improve neurodegenerative conditions where anti-inflammatory drugs fail?
}

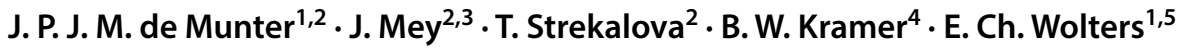

Received: 31 December 2019 / Accepted: 9 March 2020 / Published online: 6 April 2020

(c) The Author(s) 2020

\begin{abstract}
Neurodegenerative disorders share the final degenerative pathway, the inflammation-induced apoptosis and/or necrosis, irrespective of their etiology, be it of acute and chronic traumatic, vascular and idiopathic origin. Although disease-modifying strategies are an unmet need in these disorders, lately, (pre)clinical studies suggested favorable effects after an intervention with bone marrow-derived stromal cells (bm-SC). Recent interventions with intrathecal transplantation of these cells in preclinical rodent models improved the functional outcome and reduced the inflammation, but not anti-inflammatory drugs. The benefit of bm-SCs was demonstrated in rats with an acute (traumatic spinal cord injury, tSCI) and in mice with a chronic [amyotrophic lateral sclerosis (ALS)-like FUS 1-358 or SOD1-G93-A mutation] neurodegenerative process. BmSCs, were found to modify underlying disease processes, to reduce final clinical SCI-related outcome, and to slow down ALS-like clinical progression. After double-blind interventions with bm-SC transplantations, Vehicle (placebo), and (non) steroidal anti-inflammatory drugs (Methylprednisolone, Riluzole, Celecoxib), clinical, histological and histochemical findings, serum/spinal cytokines, markers for spinal microglial activation inclusive, evidenced the cell-to-cell action of bm-SCs in both otherwise healthy and immune-deficient tSCI-rats, as well as wild-type and FUS/SOD1-transgenic ALS-like mice. The multi-pathway hypothesis of the cell-to-cell action of bmSCs, presumably using extracellular vesicles (EVs) as carriers of messages in the form of RNAs, DNA, proteins, and lipids rather than influencing a single inflammatory pathway, could be justified by the reported differences of cytokines and other chemokines in the serum and spinal tissue. The mode of action of bm-SCs is hypothesized to be associated with its dedicated adjustment of the pro-apoptotic glycogen synthase kinase- $3 \beta$ level towards an anti-apoptotic level whereas their multi-pathway hypothesis seems to be confirmed by the decreased levels of the pro-inflammatory interleukin (IL)- $1 \beta$ and tumor necrosis factor (TNF) as well as the level of the marker of activated microglia, ionized calcium binding adapter (Iba)-1 level.
\end{abstract}

Keywords Spinal cord injury (SCI) - Amyotrophic lateral sclerosis (ALS) $\cdot$ Human stromal/stem cells $\cdot$ Neuro-cells . Microglial activation $\cdot$ Methylprednisolone $\cdot$ Celecoxib $\cdot$ IL-1 $\beta \cdot$ IL-6 $\cdot$ GSK-3ß $\cdot$ IBA-1

E. Ch. Wolters

ech.wolters@gmail.com

1 Neuroplast BV, Urmond, The Netherlands

2 Division 3, Translational Neuroscience, School for Mental Health and Neuroscience, Maastricht University, Maastricht, The Netherlands

3 Hospital Nacional de Parapléjicos, Toledo, Spain

4 Department of Paediatrics, University Medical Centre (MUCM), Maastricht, The Netherlands

5 Department of Neurology, UniversitatsSpital Zurich, Zurich, Switzerland

\section{Introduction}

Neurodegenerative disorders are becoming increasingly prevalent and are a growing burden on the population worldwide. Acute neurodegenerative disorders are caused by trauma or vascular problems, leading to apoptosis and inflammation. Though many molecular and genetic causes are thought to serve as predisposing or disease-propagating factors, the underlying pathogenesis in chronic neurodegenerative disorders such as amyotrophic lateral sclerosis (ALS) is in most cases still obscure. Recent discoveries in these diseases, though, have demonstrated the presence of inflammation propagating substrates, and trials with several potential 
immune-modulating therapies provided increasing evidence that primary induced apoptosis followed by secondary inflammation are heavily involved in the pathogenesis not only in acute but also in chronic neurodegenerative diseases. Although steroidal and non-steroidal anti-inflammatory drugs (N)SAIDs, with their anti-inflammatory effects, as well as various neurotrophic factors, with their pro-survival signaling mechanisms, in the past had been proven to be effective in attenuating neuronal death in many in vitro and in vivo models of neurodegeneration, all larger phase II/ III trials with both (N)SAIDs and/or various neurotrophic factors, so far, did bring equivocal and/or worse outcomes (Gilgun-Sherki et al. 2006; Hernan et al. 2006; McGeer and McGeer 2007; Schwartz and Ziv 2008; Schwartz and Shechter 2010; Bracken 2012; Ling et al. 2016). Maybe wrong timing of administration, nonselective inhibition of COX-2 or Rho-A, sub-optimal dose in target site, or limited penetration to the brain through the blood-brain barrier here may have played a role. Differences between rodent models and humans aside, perhaps the most confounding factor might be that the point(s) of action might be downstream of the pathophysiological process and retrospective in terms of neuronal death induction. Neuroprotection via pro-survival signaling also might not adequately annihilate the continuing pathological insult or might be too late to reverse the demise of compromised neurons (Tang 2017).

Unfortunately, monitoring inflammation by identifying microglia-produced cytokines as biomarkers to help in the diagnosis, to predict the progression, and to target key immune factors in the various neurodegenerative processes is still a challenge. The translation of cytokines as a biomarker in clinical practice is further hampered by intra-individual variation, environmental factors, genetic background, disease stage, and anatomical onset of motor neuron impairment (Hu et al. 2017; McCauley and Baloh 2019; MorenoMartinez et al. 2019a, b). Even age and gender play a role, and the different pro- and anti-inflammatory cytokines along the disease progression, therefore, should be further studied to understand its time point activation and its relation to other molecular and clinical mediators in neurodegeneration to finally provide a better monitoring of disease progression (Moreno-Martinez et al. 2019a).

Various genetic and environmental factors underly neurodegeneration, the result from activated inflammasomes, responsible for the activation of inflammatory responses removing cell debris, wastes and pathogens via phagocytosis. Inflammasomes are key signalling platforms that detect pathogenic microorganisms and sterile stressors, and that activate highly pro-inflammatory cytokines. In terms of molecular pathogenesis, neurodegenerative disorders share a negative contribution of non-neuronal cells (immune cells, glial cells) expressing and activating inflammasomes as a significant commonality (Lewis et al. 2012; Orsini et al. 2015).

Microglia, the resident immune cells in the CNS, comprise an entire spectrum of phenotypes that span the range from deleterious to regulatory to remodeling effects. Although microglial activation provides a defense against injury and infection, chronic or excessive activation is considered to be detrimental and has been implicated in many neurodegenerative and psychiatric disorders (Hammond et al. 2019). In response to their environment, microglia are able to rapidly change morphology and function (London et al. 2013). Gene expression analyses led to the identification of homeostatic (state 1 microglia) as well as "diseaseassociated" microglial phenotypes (DAMs) (Keren-Shaul et al. 2017). As DAMs are not associated with the disease etiology, but rather with a general response program that is involved in clearance of the protease-resistant misfolded and aggregated proteins, one still rather prefers the name "reactive" microglia. Out of the enormous variety of reactive microglia, two main types of reactive microglia have been defined: the classically activated (cytotoxic) (state 2) microglia that affect neuronal survival and that secrete pro-inflammatory cytokines, tumor necrosis factor (TNF), interleukins- $1 \beta$ and 12 (IL-1 $\beta$, IL-12), interferon-gamma (IFN- $\gamma$ ), and nitric oxide inclusive, the so-called interferon response microglia (IRMs); and the alternatively activated (cytoprotective) microglia that express genes involved in innate immune response, thus supporting an anti-inflammatory response and preventing classical microglial activation, called activated response (state 3) microglia (ARMs). ARM-response overlaps with the DAM-response described by Keren-Shaul (Keren-Shaul et al. 2017), but these cells are not necessarily disease associated and might be considered part of the normal evolution of microglia in healthy aging. At odds with the original DAM-response description is also the heterogeneity in the ARMs. Alternatively, activated microglia secrete interleukin-4 (IL-4), interleukin-13, or transforming growth factor $\beta$ (Hammond et al. 2019). Distinct 'reactive' microglia signatures can be used to better understand microglia function and to identify and manipulate specific subpopulations in health and disease. The ionized calcium-binding adapter marker (Iba)-1, which is upregulated in reactive microglia (IRM and ARM), is often used to identify these cells in general (Sala-Frigerio et al. 2019).

In acute neurodegenerative disorders, the classical activated microglia response (IRM) is caused by primary insultinduced necrosis, whereas in chronic disorders, ongoing activation is elicited by a genetic and/or environmental-driven abnormal accumulation of misfolded proteins, mitochondrial dysfunction, oxidative stress and/or inflammation, all processes which reinforce each other (Lim et al. 2007; Ganguly et al. 2017). In ALS, as with other neurodegenerative 
diseases, the degeneration is a complex interplay between multiple pathogenic cellular mechanisms such as oxidative stress, mitochondrial dysfunction, impaired axonal transport, excitotoxicity, protein aggregation, endoplasmic reticulum stress, neuroinflammation, abnormal RNA processing, nonneuronal cells, and target muscle contribution (Mancuso and Navarro 2015).

Activated cells proliferate and form dense clusters around the cell bodies of injured neurons (Ramirez et al. 2011). These classically reactive phenotypes of intrinsic microglia and/or monocyte-derived macrophages produce a proinflammation signal cascade by the secretion of various cytotoxic factors, pro-inflammatory signaling molecules, and the expression of immune molecules, TNF and other inflammatory cytokines inclusive. They also increase their expression Iba-1. Once classically activated, state 2 microglia start to express glycogen synthase kinase-3 $\beta$ (GSK-3 $\beta$ ), what they normally not do (Tang et al. 2015), thus further promoting both innate and adaptive immune responses (Wang et al. 2011; Beurel et al. 2015). GSK-3 $\beta$, though, has an interesting paradoxical effect: a high dose initiates a pro-apoptotic effect during mitochondrial-mediated intrinsic apoptosis but in a low dose, it induces an anti-apoptotic effect during death receptor-mediated extrinsic apoptosis. Low doses of GSK-3 inhibitors, therefore, provide a feasible means to counteract excessive inflammation and induce neuroprotective actions in chronic neurodegenerative conditions, among them amyotrophic lateral sclerosis (MazzardoMartins et al. 2012). Activation of microglia is a hallmark of brain pathology, and reactive microglia are especially thought to be involved in neuroinflammatory responses (Ito et al. 1998). As a consequence, the environment around the damaged neurons becomes toxic, thus further enhancing the degeneration (Subramaniam and Federoff 2017).

Once the inciting event has been adequately resolved, a lower production of pro-inflammatory cytokines will polarize these cells, switching them from state 2 microglia (IRMs) into state 3 microglia (ARMs) that express genes involved in innate immune response, facilitating phagocytosis of cell debris and misfolded proteins, promoting tissue repair, and supporting neuronal survival by neurotrophic factors (Khalid et al. 2017).

However, when the pathogenic stimulus cannot be adequately cleared, chronic inflammation develops with a persistent IRM response that can cause unintended injury to local tissues. Thus, chronic neurodegeneration is facilitated by the lack of neurotrophic growth factors and by the continued production of cytotoxic by-products of a pro-inflammatory response (Hooten et al. 2015). The type, location and connections of the necrotic cell populations are leading in the (variable) clinical expression of these neurodegenerative processes.

\section{Anti-inflammatory drug interventions in neurodegeneration}

As discussed above, neurodegenerative diseases share strong neuroinflammatory multi-pathway components, which are at least in part responsible for the continuing cell death. Pharmacological treatments, therefore, should intend to reduce this inflammatory response. Curiously, so far, interventions with anti-inflammatory drugs in patients suffering from these disorders did not result in successful treatments (Gilgun-Sherki et al. 2006; Hernan et al. 2006; McGeer and McGeer 2007; Schwartz and Ziv 2008; Schwartz and Shechter 2010; Ling et al. 2016). In patients suffering acute neurodegeneration such as spinal cord injuries, in which secondary inflammatory processes are mainly responsible for final clinical outcome, initially it was suggested that methylprednisolone (MP) did significantly reduce disability, though this could not be confirmed in later studies, and side effects appeared to outweigh any beneficial effects (Hurlbert 2000; Bracken 2012). Also, in patients suffering from chronic neurodegenerative disorders, Alzheimer disease, Parkinson disease and amyotrophic lateral sclerosis (ALS) inclusive, antiinflammatory drugs were found to be ineffective (Fondell et al. 2012; Collins and Bowser 2017; Khalid et al. 2017; Crisafulli et al. 2018). Activation of microglia and astrocytes with increased levels of pro-inflammatory serum and CSF cytokines IL-1 $\beta$, IL-6, IL-8, TNF and vascular endothelial growth factor (VEGF) is considered the hallmark in ALS (Ciervo et al. 2017; Hu et al. 2017; Morello et al. 2017; Crisafulli et al. 2018). Interventions with corticosteroids and/or other anti-inflammatory drugs such as the COX-2 inhibitor celecoxib, which causes the reduction of the brain levels of inflammatory cytokines TNF and IL-1 $\beta$ (Osman et al. 2016), however, were found ineffective in experimental ALS-like animals and/or ALS patients (Galbiati et al. 2012; Collins and Bowser 2017; Crisafulli et al. 2018). Apart from an eventual, subtle, inconsistent increase of survival time in ALS which might be seen in some patients after an intervention with riluzole (Miller et al. 2012) and/or edaravone (Yoshino and Kimura 2006), disease-modifying interventions, for instance, adequate inflammasome-targeted strategies, are still an unmet need in most neurodegenerative disorders (Voet et al. 2019). Further, growth factors may play a potential role in facilitating functional recovery in degenerative neurons (Shruthi et al. 2017). 


\section{Interventions with BM-derived stromal cells in neurodegeneration}

Although interventions with anti-inflammatory drugs in experimental neurodegenerative animal studies have not resulted in successful clinical trials, a more recent approach to treat such disorders, in both experimental animals and humans, with implanting bone marrowderived stromal cells (bm-SCs), seems very promising. Such transplants supposedly modulate the immune system in both acute (Deda et al. 2008; Martinez et al. 2017; Tsai et al. 2018; Cofano et al. 2019; Jin et al. 2019) and chronic (Mazzini et al. 2016; Ciervo et al. 2017; Gashmardi et al. 2017; Sykova et al. 2017; Cizkova et al. 2018; Garbuzova-Davis et al. 2018; Oh et al. 2018; Gugliandolo et al. 2019) neurodegenerative disorders in experimental animals as well as in patients. Our own experiments with human bm-SC in experimental animal models of both an acute (traumatic spinal cord injury; tSCI) (de Munter et al. 2019a; Romero-Ramirez et al. 2020) and a chronic neurodegenerative disorder (amyotrophic lateral sclerosis; ALS) (de Munter et al. 2019b) were fully in line with these findings. In these studies, fresh bm-SCs specimen were manufactured into standardized preparations for intrathecal application, to bring naïve stem cells into the environment where neuroinflammation and degeneration are ongoing. Hereto, these specimens were reduced in volume after positive depletion of erythrocytes, monocytes and lymphocytes and negative selection of untouched stem cells (Neuro-cells: patent WO2015/059300A1).

We explored the effect of an intrathecal transplantation with bm-SCs $\left(4 \times 10^{5} \mathrm{CD} 34^{+}\right.$cells $)$in both T-cell-deficient and immune-competent Wistar rats, 1 day after a traumatic spinal cord injury, resulting in a complete paraplegia (de Munter et al. 2019a; Romero-Ramirez et al. 2020). BmSCs were found to be free of side effects, to significantly protect for SCI-related mortality, and to improve natural motor recovery (Basso et al. 1995) compared to placebotreated animals, in the following weeks (de Munter et al. 2019a). When compared to an acute 48-h intra-peritoneal high-dose methylprednisolone (MP) application (RomeroRamirez et al. 2020), bm-SC again significantly improved locomotor functions (Basso et al. 1995) and restored body weight. Bm-SC-treated rats also never evidenced SCIassociated neuropathic pains during testing of mechanical nociception (von Frey), as sporadically seen in SCI rats treated with placebo and/or MP. In those experiments, there was no rejection of the transplants, and there were no adverse events.

The effects of an intrathecal intervention with bm-SCs $\left(5 \times 10^{5} \mathrm{CD}_{3} 4^{+}\right.$cells $)$were also studied in two different experimental ALS-like mice models. As the etiology of
ALS is still unclear, animal models are based on gene mutations which are found in familial cases: $\mathrm{Cu}-\mathrm{Zn}$ superoxide dismutase gene SOD1, C9ORF72, PGRN, TBK1, TARDBP, and FUS genes (Freischmidt et al. 2015; Al-Chalabi et al. 2016; Lutz 2018). Still asymptomatic 10-week-old FUS (1-358) (Shelkovnikova et al. 2013) and 12-week-old SOD1 (G93A) mutant mice (de Munter et al. $2019 b$ ) were treated with bm-SC transplantations before developing a progressive loss of motor functions, muscle atrophy and weight loss due to a fast degeneration of spinal motor neurons with denervation in the following weeks, thereby representing a relevant preclinical model for amyotrophic lateral sclerosis (ALS). Conforming with the previous studies (Uccelli et al. 2012; Boido et al. 2014; Ciervo et al. 2017), intrathecal bm-SC transplantations in FUS (1-358) and SOD1 (G93A) mutant ALS-like mice were found to significantly induce disease-modifying effects; they significantly delayed cachexia, weight loss and motor dysfunction, as well as muscle atrophy and the loss of spinal lumbar motor neuron as seen in placebotreated transgenic mice. Interventions with riluzole and/ or celecoxib at the same (pre-symptomatic) age in these animals, however, failed to slow down the development of these ALS-like symptoms in the mutant mice.

\section{Mode of action of BM-derived stromal cells}

The mode of action of bone marrow-derived stromal cells was originally postulated to be related to cellular integration by leveraging the plasticity of the stromal/stem and progenitor cells for the replacement of lost neural tissue. In addition, the mechanism was also considered to relate indirectly via cellular interactions which stimulate secretion of neurotrophic factors as well as factors affecting the immune response by modulating $\mathrm{T}$ - and $\mathrm{B}$-cell activities thereby decreasing apoptosis of neural cells and inflammatory responses (Ruppert et al. 2018). Mesenchymal stem cells (MSCs) and hematopoietic stem cells (HSCs) are the main stem cells sourced by bone marrow (Kucia et al. 2005). Both stem cell types are capable of differentiating into spindle neuron-like cells (Koshizuka et al. 2004; Sigurjonsson et al. 2005; Ye et al. 2011). Further, after harvesting, HSCs differentiate easily into pro-inflammatory cells increasing inflammation. These cells, though, can be kept in their naïve status at the same time when MSCs were present (Le Blanc and Ringden 2005).

As stem cells only sparsely pass intact blood-brain barriers (BBB) and/or CSF-brain barriers, it is most probably that eventual effects of bm-SCs are not reached by cell replacement but might rather be effectuated by communicators, signaling proteins that freely pass those barriers, though. If given intrathecally, the bm-SCs are trapped in the 


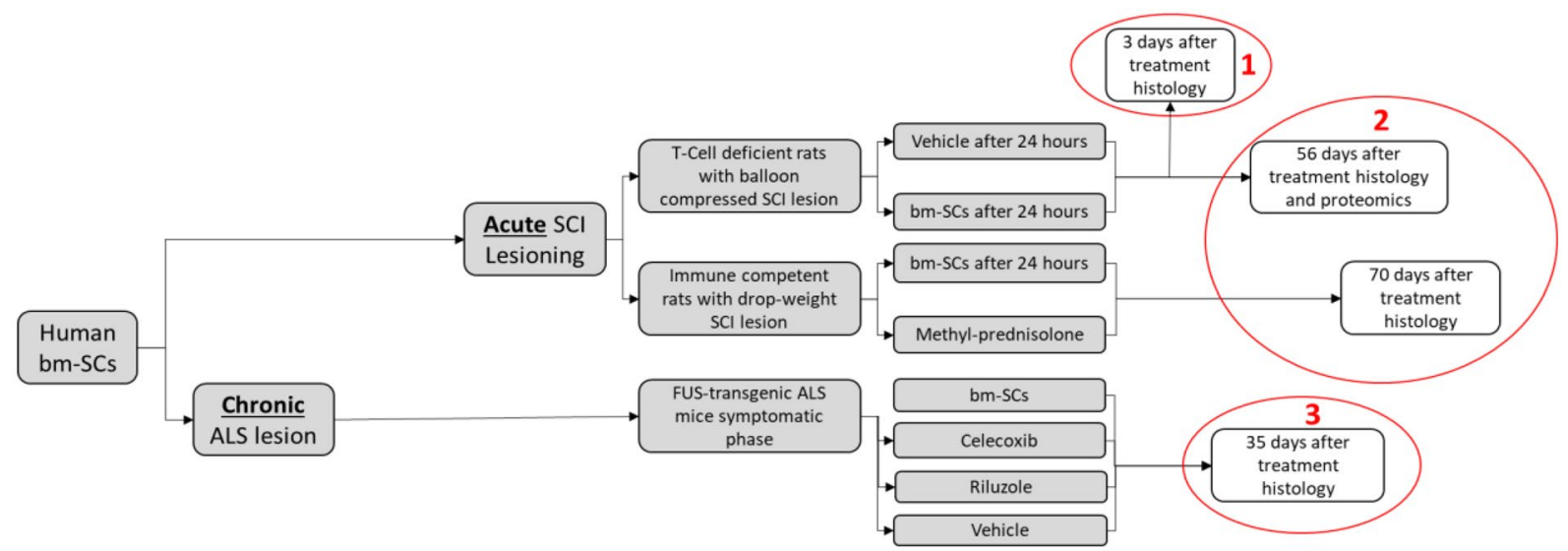

Fig. 1 Overview of the three preclinical studies, looking after the effects of an intervention with the same bm-SCs in acute and chronic degenerative diseases, providing the different time points of tissue sampling for histology

cerebrospinal fluid and disappear within a couple of weeks completely (Engelhardt and Sorokin 2009; Redzic 2011; Abramowski et al. 2016). The bm-SCs are decision-making cells that coordinate their operations with their immediate environment (Fischbach et al. 2013; Caplan 2017). They act cell-to-cell using all kinds of communicators, such as extracellular vesicles (EVs) and soluble factors such as cytokines (including chemokines, interferons, interleukins, lymphokines, and tumour necrosis factor), growth factors, and mitochondria transfer. EVs are small, membrane-bound nanoparticles that can be released from most, if not all cells, and that can carry functionally active cargo (proteins, nucleic acids) that has been shown to modify the recipient cells physiology to react in a paracrine and endocrine manner (Yanez-Mo et al. 2015; Zhang et al. 2016; Harting et al. 2018; Ruppert et al. 2018). The EVs-cargo which comprises DNA, RNA, protein, and lipids reflects the physiological as well as the pathophysiological state of a cell (Abels and Breakefield 2016). EVs are emerging as a promising tool for therapeutic delivery owing to its favorable intrinsic features of biocompatibility, stability, stealth capacity, and the ability to overcome natural barriers (Dostert et al. 2017; Shahjin et al. 2019). In other studies, bm-SC-EVs were found to exert immune-suppressive effects by enforcing ARM macrophage polarization and stimulating T-cell induction as well as producing neurotrophic factors and anti-inflammatory cytokines, as a dedicated reaction of environmental vesicles or cytokines from degenerating, malfunctioning cells (Dostert et al. 2017; Cizkova et al. 2018; Harting et al. 2018; Kim et al. 2018; Wang et al. 2018; Beers and Appel 2019; Shahjin et al. 2019). This hypothesis, though, is still a hypothesis, and recently, the possibility that bm-SCs one way or the other might donate healthy mitochondria to neurons that harbor dysfunctional mitochondria has also been raised to explain their positive effects (Babenko et al. 2015).
To further address the question why immune-modulating bm-SCs strategies are more successful than antiinflammatory drugs in human neurodegenerative disorders, we want to summarize the different cytokines and proteins with the relevant pathway and want to discuss a compilation of all findings from three preclinical studies, looking after the effects of an intervention with bm-SC in in SCI and ALS-like animal models (de Munter et al. 2019a, b; Romero-Ramirez et al. 2020). The following cytokines and proteins were studied in the mentioned preclinical experiments:

\section{TNF}

Tumour necrosis factor (TNF) is important to maintain immunity and cellular homeostasis creating a balance between cell survival, apoptosis, and necroptosis. TNF regulates the generation of reactive oxygen species (ROS) and reactive nitrogen species (RNS), and this ROS/RNS signaling plays an important role in activating and controlling inflammatory conditions (Blaser et al. 2016). Further TNF initiates the MAPK signaling pathway and the NF-kappaB signaling pathway, both involved in apoptosis and necroptosis (Wrzodek et al. 2013).

\section{IL-1 $\beta$}

Interleukin- $1 \beta$ is a pro-inflammatory cytokine and a mediator of neuronal injury. Experiments with interleukin-1 cause an impaired cerebral blood flow (Murray et al. 2015). Mechanistically, it seems that interleukin- $1 \beta$ is also correlated with the caspase pathways, thus initiating apoptosis (Spinello et al. 2019). 

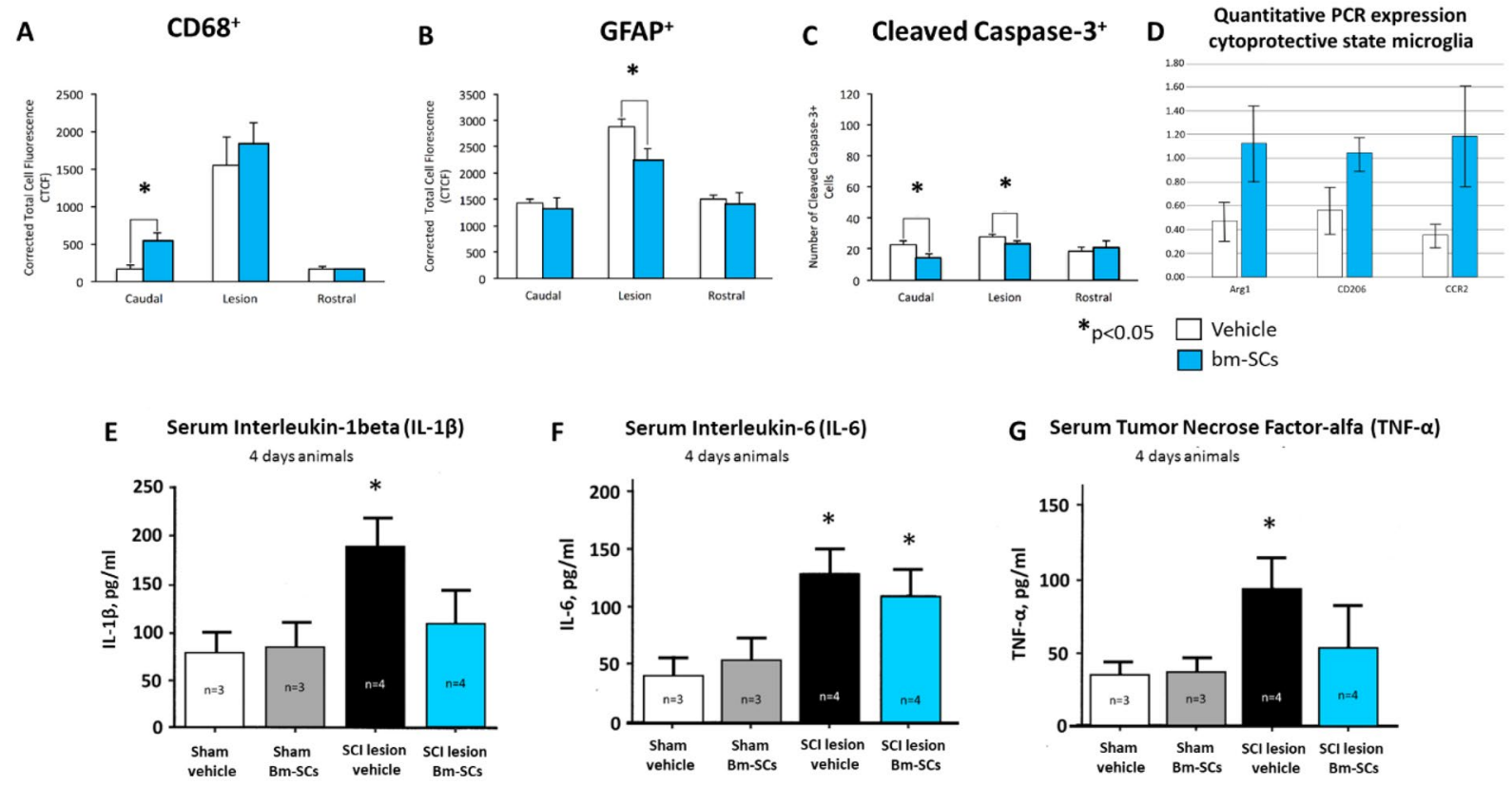

Fig. 2 Expression of microglia (a), astroglia (b), and apoptosis (c) caudal, central and rostral of the SCI lesion, and the quantified polarization from IRM to ARM microglia (d) 3 days after the interventions with bm-SCs or vehicle in T-cell-deficient balloon compres-

\section{IL-6}

Interleukin-6 is a cytokine that is released by proteolytic cleavage and is involved in the regulation of the immune system and inflammation within the central nervous system. IL-6 binds to an IL- 6 receptor, and then associates with a dimer of the ubiquitously expressed gp130 receptor subunit, which initiates intracellular signaling. Interleukin- 6 can bind to the membrane of cells (liver and leucocytes) and initiate a classical signaling, which is regenerative and anti-inflammatory, though the soluble form can bind with a co-protein to nearly all cell types and initiate trans-signaling, which is inflammatory and pro-apoptotic (Rose-John 2012). IL-6 signaling activates downstream signaling pathways such as Janus kinases/signal transducers and activators of transcription (Jak/STAT), the phosphatidylinositol 3-kinase cascade and the mitogen-activated protein kinase cascade through gp130 homodimer formation (Garbers et al. 2012).

\section{Iba-1}

Iba-1 is a marker of reactive microglia (Imai and Kohsaka 2002). Microglial activation presumably involves the FGF2/ FGFR1 (fibroblast growth factor and receptor) pathway as can be seen when this pathway is blocked (Zou et al. 2019). Microglia play an important role in modulating inflammation, and especially the polarized (ARM) microglia sion-induced spinal cord injured rats. e The serum concentration of interleukin- $1 \beta$, $\mathbf{f}$ the serum interleukin- 6 , and $\mathbf{g}$ the serum TNF levels in the sham and SCI-lesioned rats treated with vehicle or bm-SC (de Munter et al. 2019a)

contribute to a more regenerative environment. This was confirmed, as a matter of fact, by the microglial expression of arg1, CD206 and CCR2 (Roszer 2015) in our experiment (Fig. 2). However, he activation of microglia might also be reached by the modulating effects of Il-6 and TNF (Chu 2013; Schaper and Rose-John 2015).

\section{GSK-3 $\beta$}

Glycogen synthase kinase-3 is responsible for maintaining selective intracellular phosphorylation of many substrates. This enzyme is involved in all kinds of roles in multiple signaling pathways. The upregulation of GSK-3 $\beta$ expression in T cells is seen as pathogenic in autoimmune diseases (Beurel et al. 2013). Blocking GSK-3 may bring down disease progression in neurodegenerative diseases by decreasing inflammation and apoptosis, and providing a cell-protective environment (Morales-Garcia et al. 2013).

Figure 1 presents an overview of the time axis of these three studies in which we compared the histological effects of bm-SC with the effects reached after matched interventions with placebo (vehicle), methyl prednisolone, riluzole and/or Celecoxib in SCI-lesioned and ALS-like experimental animals, at different time points after intrathecal application $(1,2$, and 3$)$. The findings will be put into the perspective of the hypothesis that stem cells are decision-making cells and that they adapt to their environment. 
A

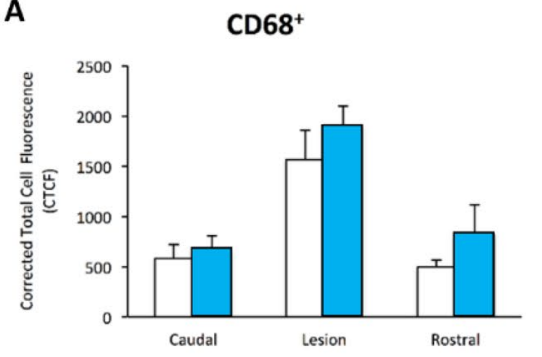

B

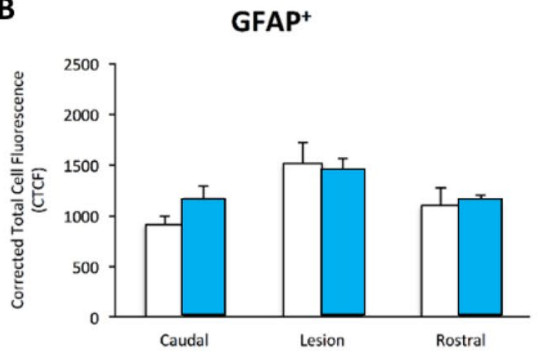

C

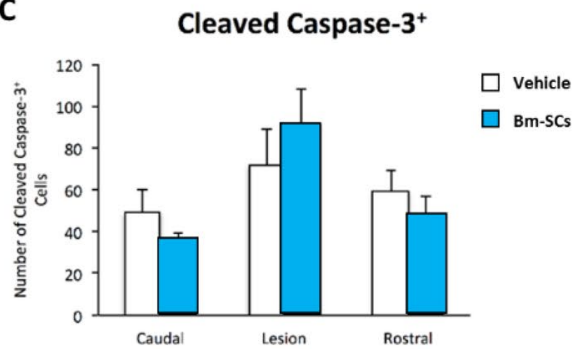

D

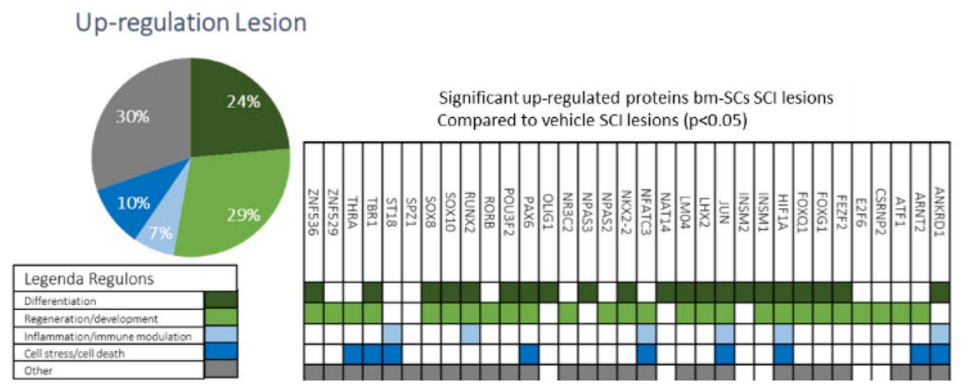

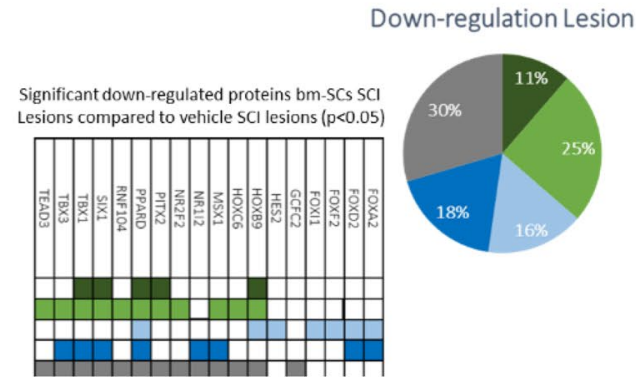

Fig. 3 Expression of microglia (a), astroglia (b) and apoptosis (c) caudal, central, and rostral of the SCI lesion in the spinal cord of animals killed 56 days after the intervention with bm-SCs or vehicle, in T-cell-deficient balloon compression-induced spinal cord-injured rats.
In $\mathbf{d}$, the significant $(p<0.05)$ up- and down-regulated proteins of the analyzed lesioned spinal tissue are presented. Protein expression in the injured tissues of the vehicle-treated animals are displayed in the baseline (de Munter et al. 2019a)
At the time point marked with number 1 in the red circle (Fig. 1), 3 days after the administration of the intrathecal intervention with bm-SCs or vehicle and 4 days after the initial lesioning, histology was performed of the spinal tissue in both balloon compression-induced SCI-lesioned and sham-lesioned immune-deficient rats (caudal, central, and rostral of the eventual lesion). Findings are displayed in Fig. 2. Naïve bm-SCs applied $24 \mathrm{~h}$ after the lesioning straight to the cerebrospinal fluid of a SCI injured rat were able to polarize IRMs into ARMs, to decrease astrocytes in the lesion, to protect neurons for apoptosis in the lesion and to decrease serum pro-inflammatory interleukins (IL$1 \beta$, IL-6, and TNF) when compared to the vehicle-treated animals. The focus of the bm-SC cells was to "detox" the cerebrospinal fluid and save precious neurons in an acute neurodegenerative condition (de Munter et al. 2019a).

At the time point marked with number 2 in the red circle (Fig. 1), 56 days after the administration of the intrathecal intervention with bm-SCs or vehicle and 57 days after the initial balloon compression-induced lesioning in immunedeficient rats, histology was performed of the spinal tissue (caudal, central, and rostral of the lesion) and lesion tissue was prepared for proteomics to investigate the up- and downregulation of different regulons. Findings at this time point are displayed in Fig. 3.
At the time point also marked with number 2 in the red circle (Fig. 1), 70 days after the administration of the intervention with bm-SCs, methylprednisolone or vehicle, and 71 days after the initial drop-weight lesioning of otherwise healthy rats, lesion site, expression of astroglia and Western blot Iba-1 in the spinal lesion site were investigated. Findings are displayed in Fig. 4.

Finally, at the time point marked with number 3 in the red circle (Fig. 1), 35 days after the application of vehicle, bmSCs, riluzole or celecoxib in still asymptomatic ALS-like FUS-mutated mice, ELISA serum and spinal Western blot histology were performed (de Munter et al. 2019b). Findings are displayed in Fig. 5.

As shown in Fig. 2, 3 days after the intervention with the vehicle, the devastating effects of the SCI lesioning in the vehicle-treated rats were mainly found due to a persistent neuroinflammatory response, as reflected by the increased expression of microglia in IRM mode, as well as the increased astrogliosis and apoptosis, when compared to the animals treated with bm-SC (de Munter et al. 2019a).

The results reached at the various time points after the interventions with bm-SCs are summarized in Table 1.

Fifty-six days after the interventions, histological studies of the lesioned tissues in the bm-SC and vehicle-treated SCIlesioned animals did not establish any significant difference 

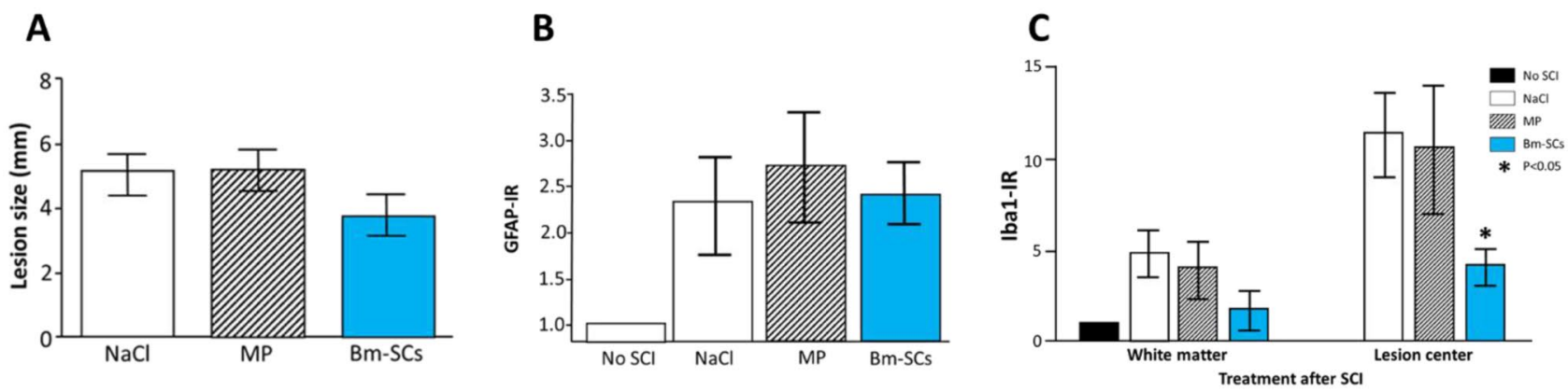

Fig. 4 Lesion size as evaluated with cleaved Caspase-3 (a), expression of astroglia (b) and Western blot Iba-1 (c) in the spinal cord tissue [data were normalized to Iba1-IR in the white matter of the not-lesioned (No SCI) rats] in immune competent rats after a drop- weight-induced SCI lesion, 70 days after an intervention with methylprednisolone (MP), vehicle $(\mathrm{NaCl})$ or human stem cells (bm-SCs) (Romero-Ramirez et al. 2020)

Table 1 Summary of the effects of interventions with intrathecally applied bm-SC in experimental animal models for both acute (SCI) and chronic (ALS-like) neurodegenerative disorders

Intrathecal application $24 \mathrm{~h}$ after SCI lesioning

Intrathecal application in still aymptomatic ALS-like FUS-tg mice (see Fig. 5)
Cytokine TNF $\downarrow(p<0.05)$ in serum and spinal tissue

Cytokines IL-1 $\beta \downarrow(p<0.05)$ and $\downarrow$ IL-6 (trending)

Iba- $1 \downarrow(p<0.05)$ in serum and spinal tissue

Polarize cytotoxic macrophages 2 (IRMs) into cytoprotective macrophages 3 (ARMs) apoptotic/pro-inflammatory proteins $\downarrow(p<0.05)$

Regenerative/differentiating proteins $\uparrow(p<0.05)$

Cytokine IL-1ß $\downarrow$ and IL-6 levels $\downarrow$ in serum and spinal tissue $(p<0.05)$

Iba- $1 \downarrow(p<0.05)$ in serum and spinal tissue

GSK-3 $\beta \downarrow(p<0.05)$ in spinal tissue in the expression of microglia, astrocytes, and apoptosis anymore (see Fig. 3). A comprehensive proteomic profile of the lesioned spinal tissue showed various changes in the up- and downregulation of the protein expression when compared with the findings at baseline (vehicle treated animals), which were set to $100 \%$. The most important findings were the downregulation of pro-inflammatory proteins and the upregulation of the proteins involved in axonal and cellular regeneration.

As might be appreciated in Fig. 4, 70 days after the intervention with vehicle, methylprednisolone or bm-SC in dropweight-induced SCI-injured, otherwise healthy, rats, the absence of any significant difference in histological findings as established 56 days after the intervention with bm-SC and vehicle-treated SCI-lesioned immune-deficient rats, as displayed in Fig. 3, could be confirmed in immunocompetent rats. The lesion size in the animals treated with bm-SCs was somewhat smaller than in the rats treated with vehicle and methylprednisolone, but not significantly. An interesting finding, though, was the significantly lower expression of Iba-1 in the lesion site of the animals treated with bmSCs, but not in the animals treated with methylprednisolone and/or vehicle (Romero-Ramirez et al. 2020) confirming the hypothesis that bm-SCs reach anti-inflammatory effects by different means than pharmacological interventions.

In these animals, apoptosis, as evaluated with activated caspase-3, was found significantly reduced in the ventral horns as well as axonal pathology in the ascending dorsal columns when compared to vehicle and/or MP-treated rats (Romero-Ramirez et al. 2020) (Fig. 4).

The most straightforward answer to the initial question about the mode of action of bm-SCs seems to be the multi-pathway approach of bm-SCs in contrast to the single pathway approach of (N)SAIDS. An alternative explanation could be the activation of a still not clear pathway more upstream of the inflammatory cascades. Bm-SCs might be seen as decision-making cells that coordinate their operations with their immediate environment (Fischbach et al. 2013; Caplan 2017). Their cell-to-cell communication here may play a major role and future research must elucidate the content of stem cell-secreted EVs in modulating inflammatory environments.

In summary, bm-SCs' immune-modulating properties, including their paracrine cytokines with their polarizing effect on IRMs, attack more and different mechanisms than the individual anti-inflammatory drugs, as also suggested by our proteomic findings in the SCI rats (de Munter et al. 


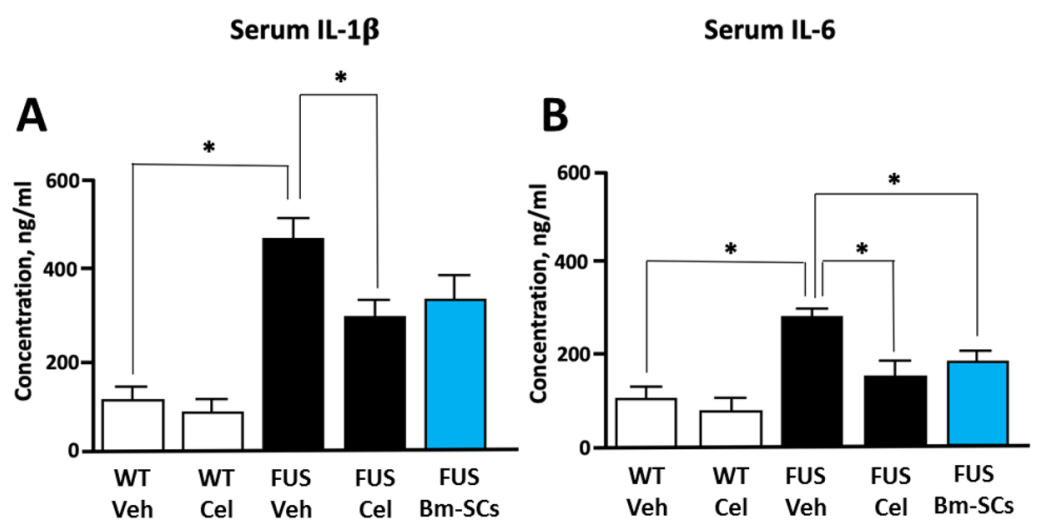

C

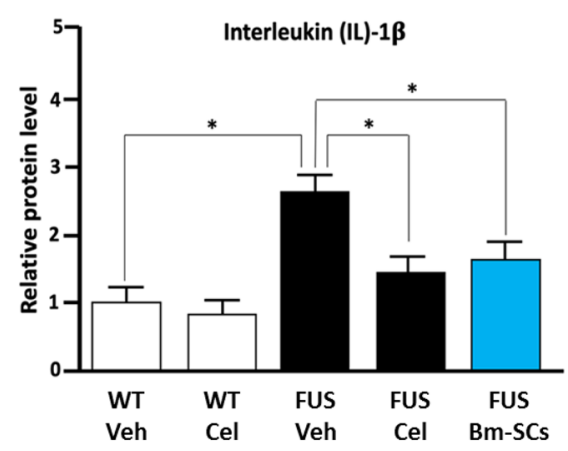

D
E
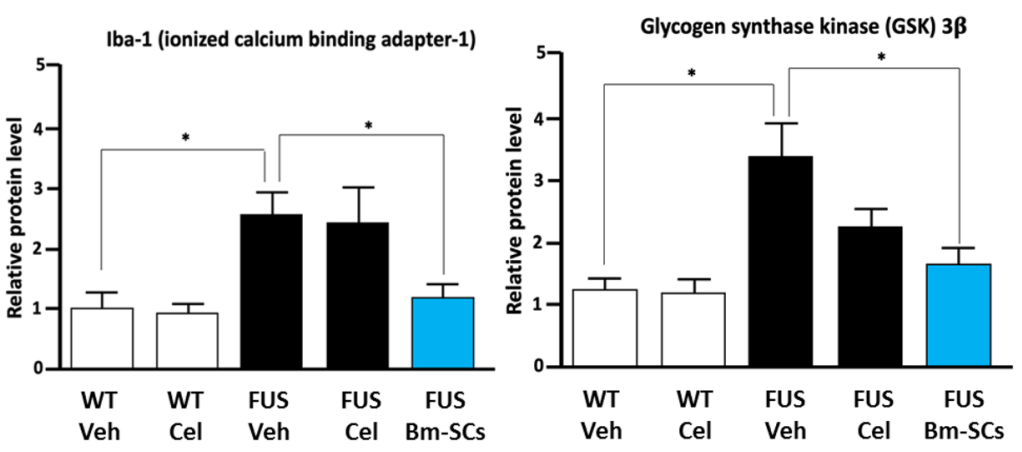

Fig. 5 Overview of the ELISA serum IL-1 $\beta$ (a) and IL-6 (b) levels, and the Western blot staining of spinal IL-1 $\beta$ (c), Iba-1 (d) and GSK-3 $\beta$ (e) levels in wild-type (WT) and FUS-tg mice treated with vehicle, riluzole, celecoxib and bm-SCs as established 35 days after these interventions in the at-that-time asymptomatic animals (de Munter et al. 2019b) 2019a). Despite the evidence that inflammation is critical in both SCI and ALS, treatment with various anti-inflammatory drugs (including Rho-A, COX-2 and TNF inhibitors, steroids, cyclophosphamide, cyclosporine, cytochrome-C inhibitors, and caspase-reducing drugs) seems to fail to clinically significant modify SCI and/or ALS symptomatology and/or pathology in humans (Hurlbert 2000; Bracken 2012; Collins and Bowser 2017; Crisafulli et al. 2018), unless the result of insufficient dosage or bioavailability, delayed time points of delivery, and/or or the taking-over of the eventually inhibited pathway by other single or downstream pathways. By the way, the bm-SC-induced immunomodulatory and regenerative effects might also be mediated when the stem cells quickly pass on their effects to resident cells (Eggenhofer et al. 2014). Figure 6 illustrates the multi-pathway approach of bm-SCs.

As for the application route of stem cells in patients suffering from neurodegenerative disorders, in our opinion, bm-SC might be best implanted intrathecally. Intravenous application ends up with most bm-SCs stuck in lung and liver (Fischer et al. 2009), and the number of engrafted bm$\mathrm{SCs}$ in the central nervous system will be minimal due to the lack of ability to easily cross the blood-brain barrier by these cells (Cerri et al. 2015). On top of this, repeated intrathecal bm-SC transplantations proved to be safe and feasible, and are found most promising for the treatment of patients with neurological diseases (Pan et al. 2019).

\section{Conclusion}

\section{Evidence is provided for bm-SCs to}

1. significantly improve survival and accelerate natural motor recovery in rats suffering balloon compression and/or weight-induced spinal cord injuries with a complete paraplegia in combination with reduced apoptosis, whereas methylprednisolone failed to do so;

2. significantly delay the onset of ALS-like symptoms in pre-symptomatic FUS- and SOD1-transgenic mice, whereas riluzole and celecoxib failed to do so.

These effects may be initially reached by bm-SCs preventing the neurodegeneration-induced inflammatory reaction 


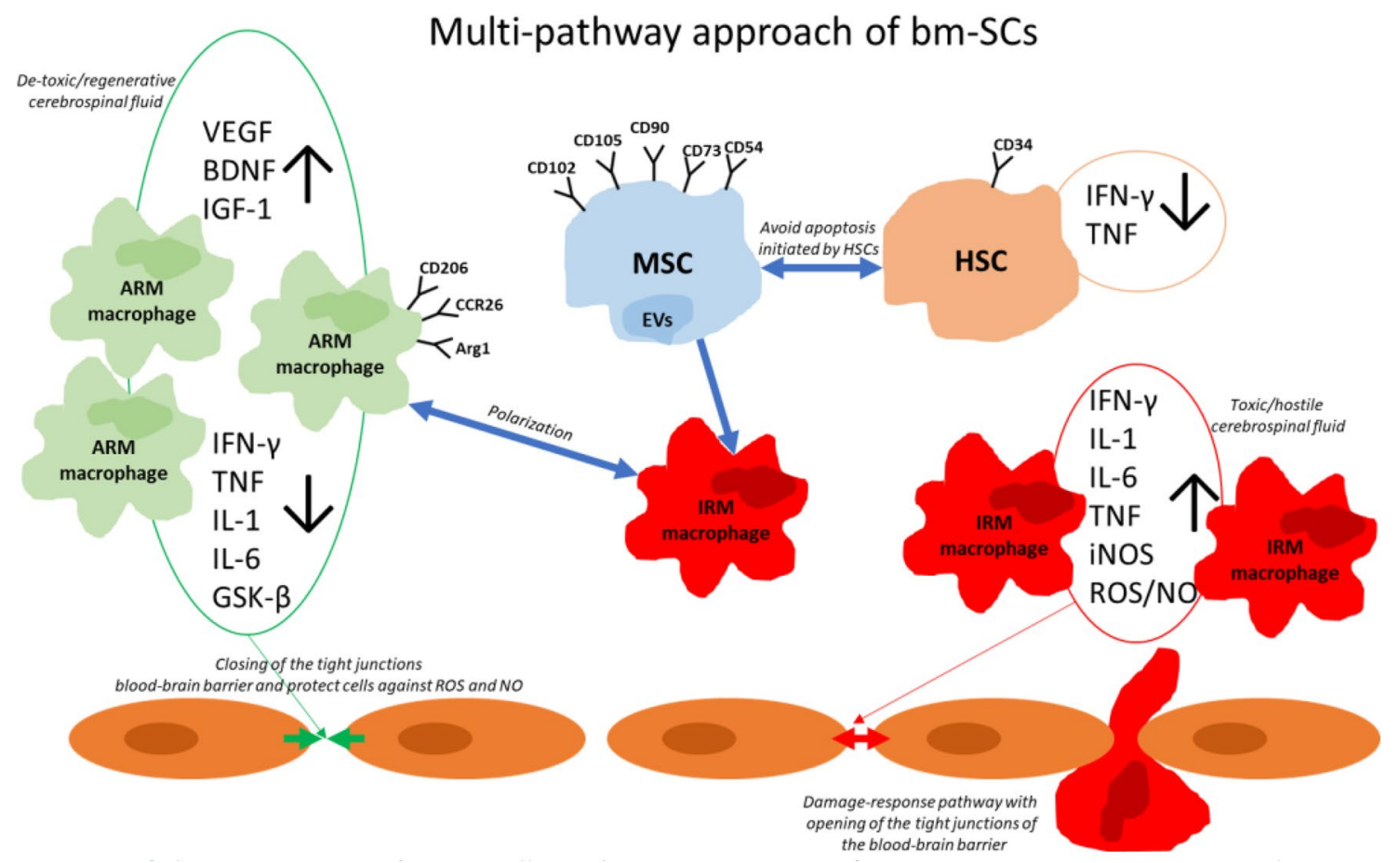

Fig. 6 An overview of the interaction of stem cells in the maintenance of a regenerative non-toxic cerebrospinal fluid. The MSCs by cell-to-cell communication polarize the IRM macrophages into ARM macrophages. The ARM macrophages decrease the pro-inflammatory cytokines and enhance the growth factors. ARM macrophage gene expression for CD206, CCR26, and Arg1. ARM activated response microglia, $B D N F$ brain-derived neurotrophic factor, $E V s$ extracellular

with sharply increased serum/spinal Il-1 $\beta$ and TNF levels, later on, having passed their effects to resident cells, in combination with bringing down the pro-inflammatory and pro-apoptotic degeneration-induced effects, as evidenced by their reduction of raised GSK-3 $\beta$ and the conversion of IRM microglia into ARM microglia. As (N)SAIDs are clinically ineffective in these acute and chronic neurodegenerative conditions, bm-SCs here might reach their effects by reducing specifically the increased GSK-3 $\beta$ and Iba- 1 protein levels in the affected central nervous system. It is possible that bm-SCs might reach these effects by acting on other than myeloid cells. Finally, the fact that bm-SCs can adapt their activity depending the environment where they are in, justifies the manufacturing/processing approach to keep these cells in a naïve condition before entering the disease arena.

Open Access This article is licensed under a Creative Commons Attribution 4.0 International License, which permits use, sharing, adaptation, distribution and reproduction in any medium or format, as long as you give appropriate credit to the original author(s) and the source, provide a link to the Creative Commons licence, and indicate if changes were made. The images or other third party material in this article are included in the article's Creative Commons licence, unless indicated otherwise in a credit line to the material. If material is not included in vesicles, GSK- $\beta$ glycogen synthase kinase-3 beta, $H S C$ hematopoietic stem cell, $I G F-1$ insulin-like growth factor- $1, I F N-\gamma$ Interferongamma, $I L-1$ interleukin-1, $I L-6$ interleukin-6, iNOS inducible nitric oxide synthase, IRM interferon response microglia, MSC mesenchymal stem cell, $N O$ nitric oxide, ROS reactive oxygen species, $T N F$ tumor necrose factor, $V E G F$ vascular endothelial growth factor)

the article's Creative Commons licence and your intended use is not permitted by statutory regulation or exceeds the permitted use, you will need to obtain permission directly from the copyright holder. To view a copy of this licence, visit http://creativecommons.org/licenses/by/4.0/.

\section{References}

Abels ER, Breakefield XO (2016) Introduction to extracellular vesicles: biogenesis, RNA cargo selection, content, release, and uptake. Cell Mol Neurobiol 36(3):301-312

Abramowski P, Krasemann S, Ernst T, Lange C, Ittrich H, Schweizer M, Zander AR, Martin R, Fehse B (2016) Mesenchymal stromal/ stem cells do not ameliorate experimental autoimmune encephalomyelitis and are not detectable in the central nervous system of transplanted mice. Stem Cells Dev 25(15):1134-1148

Al-Chalabi A, Hardiman O, Kiernan MC, Chio A, Rix-Brooks B, van den Berg LH (2016) Amyotrophic lateral sclerosis: moving towards a new classification system. Lancet Neurol 15(11):1182-1194

Babenko VA, Silachev DN, Zorova LD, Pevzner IB, Khutornenko AA, Plotnikov EY, Sukhikh GT, Zorov DB (2015) Improving the post-stroke therapeutic potency of mesenchymal multipotent stromal cells by cocultivation with cortical neurons: the role of crosstalk between cells. Stem Cells Transl Med 4(9):1011-1020 
Basso DM, Beattie MS, Bresnahan JC (1995) A sensitive and reliable locomotor rating scale for open field testing in rats. J Neurotrauma 12(1):1-21

Beers DR, Appel SH (2019) Immune dysregulation in amyotrophic lateral sclerosis: mechanisms and emerging therapies. Lancet Neurol 18(2):211-220

Beurel E, Kaidanovich-Beilin O, Yeh WI, Song L, Palomo V, Michalek SM, Woodgett JR, Harrington LE, Eldar-Finkelman H, Martinez A, Jope RS (2013) Regulation of Th1 cells and experimental autoimmune encephalomyelitis by glycogen synthase kinase- 3 . J Immunol 190(10):5000-5011

Beurel E, Grieco SF, Jope RS (2015) Glycogen synthase kinase-3 (GSK3): regulation, actions, and diseases. Pharmacol Ther 148:114-131

Blaser H, Dostert C, Mak TW, Brenner D (2016) TNF and ROS crosstalk in inflammation. Trends Cell Biol 26(4):249-261

Boido M, Piras A, Valsecchi V, Spigolon G, Mareschi K, Ferrero I, Vizzini A, Temi S, Mazzini L, Fagioli F, Vercelli A (2014) Human mesenchymal stromal cell transplantation modulates neuroinflammatory milieu in a mouse model of amyotrophic lateral sclerosis. Cytotherapy 16(8):1059-1072

Bracken MB (2012) Steroids for acute spinal cord injury. Cochrane Database Syst Rev 1:CD001046

Caplan AI (2017) Mesenchymal stem cells: time to change the name! Stem Cells Transl Med 6(6):1445-1451

Cerri S, Greco R, Levandis G, Ghezzi C, Mangione AS, FuzzatiArmentero MT, Bonizzi A, Avanzini MA, Maccario R, Blandini $F$ (2015) Intracarotid infusion of mesenchymal stem cells in an animal model of parkinson's disease, focusing on cell distribution and neuroprotective and behavioral effects. Stem Cells Transl Med 4(9):1073-1085

Chu WM (2013) Tumor necrosis factor. Cancer Lett 328(2):222-225

Ciervo Y, Ning K, Jun X, Shaw PJ, Mead RJ (2017) Advances, challenges and future directions for stem cell therapy in amyotrophic lateral sclerosis. Mol Neurodegener 12(1):85

Cizkova D, Cubinkova V, Smolek T, Murgoci AN, Danko J, Vdoviakova K, Humenik F, Cizek M, Quanico J, Fournier I, Salzet M (2018) Localized intrathecal delivery of mesenchymal stromal cells conditioned medium improves functional recovery in a rat model of spinal cord injury. Int J Mol Sci 19(3):870

Cofano F, Boido M, Monticelli M, Zenga F, Ducati A, Vercelli A, Garbossa D (2019) Mesenchymal stem cells for spinal cord injury: current options, limitations, and future of cell therapy. Int J Mol Sci 20(11):2698

Collins M, Bowser R (2017) Molecular and cellular therapies for motor neuron diseases. Academic Press, Amsterdam, pp 61-99

Crisafulli SG, Brajkovic S, Cipolat Mis MS, Parente V, Corti S (2018) Therapeutic strategies under development targeting inflammatory mechanisms in amyotrophic lateral sclerosis. Mol Neurobiol 55(4):2789-2813

de Munter JP, Beugels J, Munter S, Jansen L, Cillero-Pastor B, Moskvin O, Brook G, Pavlov D, Strekalova T, Kramer BW, Wolters EC (2019a) Standardized human bone marrow-derived stem cells infusion improves survival and recovery in a rat model of spinal cord injury. J Neurol Sci 402:16-29

de Munter J, Shafarevich I, Liundup A, Pavlov D, Wolters EC, Gorlova A, Veniaminova E, Umriukhin A, Kalueff A, Svistunov A, Kramer BW, Lesch KP, Strekalova T (2019) Neuro-cells therapy improves motor outcomes and suppresses inflammation during experimental syndrome of amyotrophic lateral sclerosis in mice. CNS Neurosci Ther. https://doi.org/10.1111/CNS.13280

Deda H, Inci MC, Kurekci AE, Kayihan K, Ozgun E, Ustunsoy GE, Kocabay S (2008) Treatment of chronic spinal cord injured patients with autologous bone marrow-derived hematopoietic stem cell transplantation: 1-year follow-up. Cytotherapy 10(6):565-574
Dostert G, Mesure B, Menu P, Velot E (2017) How do mesenchymal stem cells influence or are influenced by microenvironment through extracellular vesicles communication? Front Cell Dev Biol 5:6

Eggenhofer E, Luk F, Dahlke MH, Hoogduijn MJ (2014) The life and fate of mesenchymal stem cells. Front Immunol 5:148

Engelhardt B, Sorokin L (2009) The blood-brain and the blood-cerebrospinal fluid barriers: function and dysfunction. Semin Immunopathol 31(4):497-511

Fischbach MA, Bluestone JA, Lim WA (2013) Cell-based therapeutics: the next pillar of medicine. Sci Transl Med 5(179):179ps177

Fischer UM, Harting MT, Jimenez F, Monzon-Posadas WO, Xue H, Savitz SI, Laine GA, Cox CS Jr (2009) Pulmonary passage is a major obstacle for intravenous stem cell delivery: the pulmonary first-pass effect. Stem Cells Dev 18(5):683-692

Fondell E, O'Reilly EJ, Fitzgerald KC, Falcone GJ, McCullough ML, Thun MJ, Park Y, Kolonel LN, Ascherio A (2012) Non-steroidal anti-inflammatory drugs and amyotrophic lateral sclerosis: results from five prospective cohort studies. Amyotroph Lateral Scler 13(6):573-579

Freischmidt A, Muller K, Zondler L, Weydt P, Mayer B, von Arnim CA, Hubers A, Dorst J, Otto M, Holzmann K, Ludolph AC, Danzer KM, Weishaupt JH (2015) Serum microRNAs in sporadic amyotrophic lateral sclerosis. Neurobiol Aging 36(9):2660. e2615-2620

Galbiati M, Onesto E, Zito A, Crippa V, Rusmini P, Mariotti R, Bentivoglio M, Bendotti C, Poletti A (2012) The anabolic/androgenic steroid nandrolone exacerbates gene expression modifications induced by mutant SOD1 in muscles of mice models of amyotrophic lateral sclerosis. Pharmacol Res 65(2):221-230

Ganguly G, Chakrabarti S, Chatterjee U, Saso L (2017) Proteinopathy, oxidative stress and mitochondrial dysfunction: cross talk in Alzheimer's disease and Parkinson's disease. Drug Des Devel Ther 11:797-810

Garbers C, Hermanns HM, Schaper F, Muller-Newen G, Grotzinger J, Rose-John S, Scheller J (2012) Plasticity and cross-talk of interleukin 6-type cytokines. Cytokine Growth Factor Rev 23(3):85-97

Garbuzova-Davis S, Haller E, Navarro S, Besong TE, Boccio KJ, Hailu S, Khatib M, Sanberg PR, Appel SH, Borlongan CV (2018) Transplantation of human bone marrow stem cells into symptomatic ALS mice enhances structural and functional blood-spinal cord barrier repair. Exp Neurol 310:33-47

Gashmardi N, Hosseini SE, Mehrabani D, Edalatmanesh MA, Khodabandeh Z (2017) Impacts of bone marrow stem cells on caspase-3 levels after spinal cord injury in mice. Iran J Med Sci 42(6):593-598

Gilgun-Sherki Y, Melamed E, Offen D (2006) Anti-inflammatory drugs in the treatment of neurodegenerative diseases: current state. Curr Pharm Des 12(27):3509-3519

Gugliandolo A, Bramanti P, Mazzon E (2019) Mesenchymal stem cells: a potential therapeutic approach for amyotrophic lateral sclerosis? Stem Cells Int 2019:3675627

Hammond TR, Dufort C, Dissing-Olesen L, Giera S, Young A, Wysoker A, Walker AJ, Gergits F, Segel M, Nemesh J, Marsh SE, Saunders A, Macosko E, Ginhoux F, Chen J, Franklin RJM, Piao X, McCarroll SA, Stevens B (2019) Single-cell RNA sequencing of microglia throughout the mouse lifespan and in the injured brain reveals complex cell-state changes. Immunity 50(1):253-271.e256

Harting MT, Srivastava AK, Zhaorigetu S, Bair H, Prabhakara KS, Toledano Furman NE, Vykoukal JV, Ruppert KA, Cox CS Jr, Olson SD (2018) Inflammation-stimulated mesenchymal stromal cell-derived extracellular vesicles attenuate inflammation. Stem Cells 36(1):79-90 
Hernan MA, Logroscino G, Garcia Rodriguez LA (2006) Nonsteroidal anti-inflammatory drugs and the incidence of Parkinson disease. Neurology 66(7):1097-1099

Hooten KG, Beers DR, Zhao W, Appel SH (2015) Protective and toxic neuroinflammation in amyotrophic lateral sclerosis. Neurotherapeutics 12(2):364-375

Hu Y, Cao C, Qin XY, Yu Y, Yuan J, Zhao Y, Cheng Y (2017) Increased peripheral blood inflammatory cytokine levels in amyotrophic lateral sclerosis: a meta-analysis study. Sci Rep 7(1):9094

Hurlbert RJ (2000) Methylprednisolone for acute spinal cord injury: an inappropriate standard of care. J Neurosurg 93(1 Suppl):1-7

Imai Y, Kohsaka S (2002) Intracellular signaling in M-CSF-induced microglia activation: role of Iba1. Glia 40(2):164-174

Ito D, Imai Y, Ohsawa K, Nakajima K, Fukuuchi Y, Kohsaka S (1998) Microglia-specific localisation of a novel calcium binding protein, Iba1. Brain Res Mol Brain Res 57(1):1-9

Jin MC, Medress ZA, Azad TD, Doulames VM, Veeravagu A (2019) Stem cell therapies for acute spinal cord injury in humans: a review. Neurosurg Focus 46(3):E10

Keren-Shaul H, Spinrad A, Weiner A, Matcovitch-Natan O, DvirSzternfeld R, Ulland TK, David E, Baruch K, Lara-Astaiso D, Toth B, Itzkovitz S, Colonna M, Schwartz M, Amit I (2017) A unique microglia type associated with restricting development of Alzheimer's disease. Cell 169(7):1276-1290.e1217

Khalid SI, Ampie L, Kelly R, Ladha SS, Dardis C (2017) Immune modulation in the treatment of amyotrophic lateral sclerosis: a review of clinical trials. Front Neurol 8:486

Kim SH, Oh KW, Jin HK, Bae JS (2018) Immune inflammatory modulation as a potential therapeutic strategy of stem cell therapy for ALS and neurodegenerative diseases. BMB Rep 51(11):545-546

Koshizuka S, Okada S, Okawa A, Koda M, Murasawa M, Hashimoto M, Kamada T, Yoshinaga K, Murakami M, Moriya H, Yamazaki M (2004) Transplanted hematopoietic stem cells from bone marrow differentiate into neural lineage cells and promote functional recovery after spinal cord injury in mice. J Neuropathol Exp Neurol 63(1):64-72

Kucia M, Reca R, Jala VR, Dawn B, Ratajczak J, Ratajczak MZ (2005) Bone marrow as a home of heterogenous populations of nonhematopoietic stem cells. Leukemia 19(7):1118-1127

Le Blanc K, Ringden O (2005) Use of mesenchymal stem cells for the prevention of immune complications of hematopoietic stem cell transplantation. Haematologica 90(4):438

Lewis CA, Manning J, Rossi F, Krieger C (2012) The Neuroinflammatory response in ALS: the roles of microglia and t cells. Neurol Res Int 2012:803701

Lim JH, Byeon YE, Ryu HH, Jeong YH, Lee YW, Kim WH, Kang KS, Kweon OK (2007) Transplantation of canine umbilical cord blood-derived mesenchymal stem cells in experimentally induced spinal cord injured dogs. J Vet Sci 8(3):275-282

Ling QL, Murdoch E, Ruan KH (2016) How can we address the controversies surrounding the use of NSAIDS in neurodegeneration? Future Med Chem 8(11):1153-1155

London A, Cohen M, Schwartz M (2013) Microglia and monocytederived macrophages: functionally distinct populations that act in concert in CNS plasticity and repair. Front Cell Neurosci 7:34

Lutz C (2018) Mouse models of ALS: past, present and future. Brain Res 1693(Pt A):1-10

Mancuso R, Navarro X (2015) Amyotrophic lateral sclerosis: current perspectives from basic research to the clinic. Prog Neurobiol $133: 1-26$

Martinez A, Palomo Ruiz MD, Perez DI, Gil C (2017) Drugs in clinical development for the treatment of amyotrophic lateral sclerosis. Expert Opin Investig Drugs 26(4):403-414

Mazzardo-Martins L, Martins DF, Stramosk J, Cidral-Filho FJ, Santos AR (2012) Glycogen synthase kinase 3-specific inhibitor
AR-A014418 decreases neuropathic pain in mice: evidence for the mechanisms of action. Neuroscience 226:411-420

Mazzini L, Vescovi A, Cantello R, Gelati M, Vercelli A (2016) Stem cells therapy for ALS. Expert Opin Biol Ther 16(2):187-199

McCauley ME, Baloh RH (2019) Inflammation in ALS/FTD pathogenesis. Acta Neuropathol 137(5):715-730

McGeer PL, McGeer EG (2007) NSAIDs and Alzheimer disease: epidemiological, animal model and clinical studies. Neurobiol Aging 28(5):639-647

Miller RG, Mitchell JD, Moore DH (2012) Riluzole for amyotrophic lateral sclerosis (ALS)/motor neuron disease (MND). Cochrane Database Syst Rev 3:CD001447

Morales-Garcia JA, Susin C, Alonso-Gil S, Perez DI, Palomo V, Perez C, Conde S, Santos A, Gil C, Martinez A, Perez-Castillo A (2013) Glycogen synthase kinase-3 inhibitors as potent therapeutic agents for the treatment of Parkinson disease. ACS Chem Neurosci 4(2):350-360

Morello G, Spampinato AG, Cavallaro S (2017) Neuroinflammation and ALS: transcriptomic insights into molecular disease mechanisms and therapeutic targets. Mediat Inflamm 2017:7070469

Moreno-Martinez L, Calvo AC, Munoz MJ, Osta R (2019a) Are circulating cytokines reliable biomarkers for amyotrophic lateral sclerosis? Int J Mol Sci 20(11):2759

Moreno-Martinez L, de la Torre M, Toivonen JM, Zaragoza P, GarciaRedondo A, Calvo AC, Osta R (2019b) Circulating cytokines could not be good prognostic biomarkers in a mouse model of amyotrophic lateral sclerosis. Front Immunol 10:801

Murray KN, Parry-Jones AR, Allan SM (2015) Interleukin-1 and acute brain injury. Front Cell Neurosci 9:18

Oh KW, Noh MY, Kwon MS, Kim HY, Oh SI, Park J, Kim HJ, Ki CS, Kim SH (2018) Repeated intrathecal mesenchymal stem cells for amyotrophic lateral sclerosis. Ann Neurol 84(3):361-373

Orsini M, Oliveira AB, Nascimento OJ, Reis CH, Leite MA, de Souza JA, Pupe C, de Souza OG, Bastos VH, de Freitas MR, Teixeira S, Bruno C, Davidovich E, Smidt B (2015) Amyotrophic lateral sclerosis: new perspectives and update. Neurol Int 7(2):5885

Osman AE, Mubasher M, ElSheikh NE, AlHarthi H, AlZahrani MS, Ahmed N, ElGhazali G, Bradley BA, Fadil AS (2016) Association of single nucleotide polymorphisms in pro-inflammatory cytokine and toll-like receptor genes with pediatric hematogenous osteomyelitis. Genet Mol Res. https://doi.org/10.4238/ gma.15027718

Pan K, Deng L, Chen P, Peng Q, Pan J, Wu Y, Wang Y (2019) Safety and feasibility of repeated intrathecal allogeneic bone marrowderived mesenchymal stromal cells in patients with neurological diseases. Stem Cells Int 2019:8421281

Ramirez JJ, Poulton WE, Knelson E, Barton C, King MA, Klein RL (2011) Focal expression of mutated tau in entorhinal cortex neurons of rats impairs spatial working memory. Behav Brain Res 216(1):332-340

Redzic Z (2011) Molecular biology of the blood-brain and the bloodcerebrospinal fluid barriers: similarities and differences. Fluids Barriers CNS 8(1):3

Romero-Ramirez L, Wu S, de Munter J, Wolters EC, Kramer BW, Mey J (2020) Treatment of rats with spinal cord injury using human bone marrow-derived stromal cells prepared by negative selection. J Biomed Sci 27(1):35

Rose-John S (2012) IL-6 trans-signaling via the soluble IL-6 receptor: importance for the pro-inflammatory activities of IL-6. Int J Biol Sci 8(9):1237-1247

Roszer T (2015) Understanding the mysterious M2 Macrophage through activation markers and effector mechanisms. Mediat Inflamm 2015:816460

Ruppert KA, Nguyen TT, Prabhakara KS, Toledano Furman NE, Srivastava AK, Harting MT, Cox CS Jr, Olson SD (2018) Human mesenchymal stromal cell-derived extracellular vesicles modify 
microglial response and improve clinical outcomes in experimental spinal cord injury. Sci Rep 8(1):480

Sala-Frigerio C, Wolfs L, Fattorelli N, Thrupp N, Voytyuk I, Schmidt I, Mancuso R, Chen WT, Woodbury ME, Srivastava G, Moller T, Hudry E, Das S, Saido T, Karran E, Hyman B, Perry VH, Fiers M, De Strooper B (2019) The major risk factors for Alzheimer's disease: age, sex, and genes modulate the microglia response to abeta plaques. Cell Rep 27(4):1293-1306.e1296

Schaper F, Rose-John S (2015) Interleukin-6: biology, signaling and strategies of blockade. Cytokine Growth Factor Rev 26(5):475-487

Schwartz M, Shechter R (2010) Systemic inflammatory cells fight off neurodegenerative disease. Nat Rev Neurol 6(7):405-410

Schwartz M, Ziv Y (2008) Immunity to self and self-maintenance: what can tumor immunology teach us about ALS and Alzheimer's disease? Trends Pharmacol Sci 29(6):287-293

Shahjin F, Chand S, Yelamanchili SV (2019) Extracellular vesicles as drug delivery vehicles to the central nervous system. J Neuroimmune Pharmacol. https://doi.org/10.1007/s11481-019-09875-w

Shelkovnikova TA, Peters OM, Deykin AV, Connor-Robson N, Robinson H, Ustyugov AA, Bachurin SO, Ermolkevich TG, Goldman IL, Sadchikova ER, Kovrazhkina EA, Skvortsova VI, Ling SC, Da Cruz S, Parone PA, Buchman VL, Ninkina NN (2013) Fused in sarcoma (FUS) protein lacking nuclear localization signal (NLS) and major RNA binding motifs triggers proteinopathy and severe motor phenotype in transgenic mice. J Biol Chem 288(35):25266-25274

Shruthi S, Sumitha R, Varghese AM, Ashok S, Chandrasekhar Sagar BK, Sathyaprabha TN, Nalini A, Kramer BW, Raju TR, Vijayalakshmi K, Alladi PA (2017) Brain-derived neurotrophic factor facilitates functional recovery from ALS-cerebral spinal fluidinduced neurodegenerative changes in the NSC-34 motor neuron cell line. Neurodegener Dis 17(1):44-58

Sigurjonsson OE, Perreault MC, Egeland T, Glover JC (2005) Adult human hematopoietic stem cells produce neurons efficiently in the regenerating chicken embryo spinal cord. Proc Natl Acad Sci U S A 102(14):5227-5232

Spinello A, Vecile E, Abbate A, Dobrina A, Magistrato A (2019) How can interleukin-1 receptor antagonist modulate distinct cell death pathways? J Chem Inf Model 59(1):351-359

Subramaniam SR, Federoff HJ (2017) Targeting microglial activation states as a therapeutic avenue in Parkinson's disease. Front Aging Neurosci 9:176

Sykova E, Rychmach P, Drahoradova I, Konradova S, Ruzickova K, Vorisek I, Forostyak S, Homola A, Bojar M (2017) Transplantation of mesenchymal stromal cells in patients with amyotrophic lateral sclerosis: results of phase I/IIa clinical trial. Cell Transplant 26(4):647-658

Tang BL (2017) Amyotrophic lateral sclerosis disease modifying therapeutics: a cell biological perspective. Neural Regen Res 12(3):407-408

Tang W, Han N, Liu Y, Li Z, Wei Y (2015) GSK3beta expression and phosphorylation during neuronal maturation in the rat dorsal root ganglion. Int J Clin Exp Med 8(4):5897-5903

Tsai MJ, Liou DY, Lin YR, Weng CF, Huang MC, Huang WC, Tseng FW, Cheng H (2018) Attenuating spinal cord injury by conditioned medium from bone marrow mesenchymal stem cells. J Clin Med 8(1):23

Uccelli A, Milanese M, Principato MC, Morando S, Bonifacino T, Vergani L, Giunti D, Voci A, Carminati E, Giribaldi F, Caponnetto C, Bonanno G (2012) Intravenous mesenchymal stem cells improve survival and motor function in experimental amyotrophic lateral sclerosis. Mol Med 18:794-804

Voet S, Srinivasan S, Lamkanfi M, van Loo G (2019) Inflammasomes in neuroinflammatory and neurodegenerative diseases. EMBO Mol Med 11(6):e10248

Wang H, Brown J, Martin M (2011) Glycogen synthase kinase 3: a point of convergence for the host inflammatory response. Cytokine 53(2):130-140

Wang L, Pei S, Han L, Guo B, Li Y, Duan R, Yao Y, Xue B, Chen X, Jia Y (2018) Mesenchymal stem cell-derived exosomes reduce A1 astrocytes via downregulation of phosphorylated NF-kappaB P65 subunit in spinal cord injury. Cell Physiol Biochem 50(4):1535-1559

Wrzodek C, Buchel F, Ruff M, Drager A, Zell A (2013) Precise generation of systems biology models from KEGG pathways. BMC Syst Biol 7:15

Yanez-Mo M, Siljander PR, Andreu Z, Zavec AB, Borras FE, Buzas EI, Buzas K, Casal E, Cappello F, Carvalho J, Colas E, Cordeiro-da Silva A, Fais S, Falcon-Perez JM, Ghobrial IM, Giebel B, Gimona M, Graner M, Gursel I, Gursel M, Heegaard NH, Hendrix A, Kierulf P, Kokubun K, Kosanovic M, Kralj-Iglic V, Kramer-Albers EM, Laitinen S, Lasser C, Lener T, Ligeti E, Line A, Lipps G, Llorente A, Lotvall J, Mancek-Keber M, Marcilla A, Mittelbrunn M, Nazarenko I, Nolte-'t Hoen EN, Nyman TA, O’Driscoll L, Olivan M, Oliveira C, Pallinger E, Del Portillo HA, Reventos J, Rigau M, Rohde E, Sammar M, Sanchez-Madrid F, Santarem N, Schallmoser K, Ostenfeld MS, Stoorvogel W, Stukelj R, Van der Grein SG, Vasconcelos MH, Wauben MH, De Wever O (2015) Biological properties of extracellular vesicles and their physiological functions. J Extracell Vesicles 4:27066

Ye Y, Zeng YM, Wan MR, Lu XF (2011) Induction of human bone marrow mesenchymal stem cells differentiation into neurallike cells using cerebrospinal fluid. Cell Biochem Biophys 59(3):179-184

Yoshino H, Kimura A (2006) Investigation of the therapeutic effects of edaravone, a free radical scavenger, on amyotrophic lateral sclerosis (Phase II study). Amyotroph Lateral Scler 7(4):241-245

Zhang B, Yeo RW, Tan KH, Lim SK (2016) Focus on extracellular vesicles: therapeutic potential of stem cell-derived extracellular vesicles. Int J Mol Sci 17(2):174

Zou LH, Shi YJ, He H, Jiang SM, Huo FF, Wang XM, Wu F, Ma L (2019) Effects of FGF2/FGFR1 pathway on expression of A1 astrocytes after infrasound exposure. Front Neurosci 13:429

Publisher's Note Springer Nature remains neutral with regard to jurisdictional claims in published maps and institutional affiliations. 